\title{
Testing for Presence of Radioactivity in Food Products Imported from Japan to Canada
}

\author{
Kazuhiro Takeuchi' ${ }^{1}$, Bobby Sidhu ${ }^{2}$, and Abderrachid Zitouni ${ }^{3}$ \\ 1Lead Author, B. Tech Student, School of Health Sciences, British Columbia Institute of Technology, Burnaby, BC. \\ 2Supervisor, School of Health Sciences, British Columbia Institute of Technology, Burnaby, BC. \\ 3Mentor, Provincial Radiation Specialist, B.C. Centre for Disease Control, Vancouver, BC.
}

\begin{abstract}
Following the Fukushima Nuclear accident of March $11^{\text {th }}$ of 2011, many people, particularly among the general public are still skeptical about the safety of foods imported from Japan. Furthermore, currently little radiation monitoring of food happens in Canada. The present study aims to test for the presence or absence of gamma radioactivity in various food products imported to Canada from Japan. Thirty commonly imported Japanese and thirty-two additional Canadian food products were purchased from supermarkets and convenience stores in Vancouver, British Columbia. All samples were tested for gamma radiation from cesium-134 and cesium-137 using a portable gamma spectrometer, the EXPLORANIUM GR-135 Plus Identifier. All food samples tested in this experiment were found free of any detectable gamma radioactivity.
\end{abstract}

Key words: Japanese, Food, Fukushima, Canada, cesium-134, cesium-137, gamma radiation

\section{Introduction}

Over three years after the Fukushima Daiichi Nuclear accident in 2011, Canadians remain concerned about radioactivity in food; particularly sea food products coming from Japan (Pynn, 2014). Immediately after the accident, the Canadian Food Inspection Agency (CFIA) implemented import control measures which banned foods and animal feed products from affected areas in Japan to enter Canada without official documentation proving their innocuity (BCCDC, 2014). The CFIA also started a testing program that monitored the radiation levels of food from Japan, domestic milk and domestic fish off the coast of British Columbia. However, because all food samples tested were negative for radioactivity, the import controls were lifted and the monitoring \& sampling program was discontinued three months after the Fukushima incident (CFIA, 2011). According to Health Canada, the radiation levels that resulted from the Fukushima incident are far below the levels of concern to public health in Canada; yet, many in Canada are still skeptical about the integrity of foods with respect to radiation contamination (Health Canada, 2014). Public skepticism about radiation could be due to media bias, rumors, lack of information and lack of radiation monitoring programs. The objective of this research is to test for the presence/absence of radioactivity in various food products imported to Canada from Japan.

This research project was suggested by the Provincial Radiation Specialist Dr. Abderrachid 
Zitouni from the Environmental Health Services Division of the B.C. Centre for Disease Control.

\section{The Great East Japan Earthquake}

The Great East Japan Earthquake (Also known as 2011 Tōhoku earthquake or Higashi Nihon Daishinsai) occurred on March 11 ${ }^{\text {th }}, 2011$ at 2:46 PM; its epicenter was located approximately $70 \mathrm{~km}$ east of the Oshika Peninsula of Tohoku district in Japan (Dobashi, 2011). With a magnitude 9.0 (Ritchter scale), it is considered to be one of the top five most powerful earthquakes in the world since 1900 (Dobashi, 2011). The violent earthquake motion triggered many disasters such as fires, explosions, accidents, building destructions and tsunami waves of up to $40.5 \mathrm{~m}$ (Chiu et al, 2013). According to the National Police Agency of Japan (2014), 15,889 people were killed, 2,601 were missing and 6,152 were injured.

\subsection{Fukushima Daiichi Nuclear Power Plant Accident}

Approximately one hour after the Great East Japan Earthquake, the tsunamis that were generated hit the Fukushima Dai-Ichi Nuclear Power Plant, resulting in the take down of several electrical generators and three nuclear reactors. The nuclear reactors eventually underwent a meltdown, followed by explosions and the release of radionuclides into the atmosphere. The three most significant radionuclides released in this incident were iodine-131 $\left({ }^{131} \mathrm{I}\right)$, cesium-134 $\quad\left({ }^{134} \mathrm{Cs}\right)$ and cesium-137 ( ${ }^{137} \mathrm{Cs}$ ) (Marzo, 2014). The National Institute for Safety Agency of Japan (NISA) estimated that the amounts of radioactivity released by the three crippled reactors were 160 PBq (1PBq $=1.0 * 10^{15}$ Becquerels) of ${ }^{131} \mathrm{I}$ and 15 $\mathrm{PBq}$ of ${ }^{137} \mathrm{Cs}$. In addition, 520 ton of water containing $2800 \mathrm{TBq}$ of ${ }^{131} \mathrm{I}, 940 \mathrm{TBq}$ of ${ }^{134} \mathrm{Cs}$ and ${ }^{137} \mathrm{Cs}$ were released into the ocean within days of the meltdown (Hamada \& Ogino, 2012).
On March 11, 2011 at 7:03 PM, followed by the Fukushima nuclear plant disaster, Japan's prime minister declared a state of emergency (Hamada \& Ogino, 2012). Residents from nearby areas to the plant were evacuated, residents from surrounding areas were recommended to stay indoors and shipments of food products such as spinach and milk from areas close to the plant were banned as they were found to have radiation levels exceeding Japan's legal limits (Chiu et al, 2013).

\section{Iodine-131, Cesium-134 \& Cesium-137}

The three most significant radionuclides released into the environment after the Fukushima incident were ${ }^{131} \mathrm{I},{ }^{134} \mathrm{Cs}$ and ${ }^{137} \mathrm{Cs}$ (Marzo, 2014). ${ }^{131} \mathrm{I}$ is the unstable and radioactive version of the metal iodine. Upon its decay, ${ }^{131} \mathrm{I}$ releases a beta particle and gamma radiation. Humans can be exposed to ${ }^{131} \mathrm{I}$ through ingestion of contaminated foods; upon ingestion, iodine is accumulated in the thyroid gland. High doses of radioactive iodine may induce thyroid cancer. Lower doses of radioactive iodine may lead to reduced thyroid gland activity and hormone production (US EPA, 2002). Iodine-131 is soluble in water so it can easily accumulate in marine organisms. However, its environmental impact is low due to its 8-day half-life (US EPA, 2002).

${ }^{134} \mathrm{Cs}$ and ${ }^{137} \mathrm{Cs}$ are common byproducts fissions or the splitting of uranium. ${ }^{134} \mathrm{Cs}$ has a half-life of 2 years and it emits gamma and beta radiation as it decays to xenom-134 or barium-134, which are non-radioactive byproducts. Cesium-137 decays to barium- $137 \mathrm{~m}$ which then decays to a stable form of barium. In the first decay beta particles are released and in the second decay, gamma radiation is emitted. Cesium-137 and barium-137m have a half-life of 30 years and 2.6 minutes respectively (EPA, 2002). Radioactive cesium behaves similarly in the human body. 
Humans can be exposed to radioactive cesium through the ingestion and inhalation routes. Sources of radioactive cesium include atmospheric fallout, contaminated soil, water, foods and nuclear accidents. Once in the body, it is distributed in the body's soft tissues, with a slightly higher concentration in the muscles and slightly lower concentrations in bone and fat (US EPA, 2002). Radioactive cesiums have more significant health outcomes than radioactive iodine because of their longer halflives. Based on epidemiological studies, exposure to radioactive Cesiums, particularly Cs-137 can lead to increased risk to malignant tumors and shortening of life. In a case study, in Brazil, Goiania in 1987, about 250 civilians were accidentally exposed to ${ }^{137} \mathrm{Cs}$ sources from stolen medical equipment (Toxnet, 2006). Exposures were oral and dermal. The civilians showed signs and symptoms of acute radiation syndrome (ARS), radiation burns, ocular injury, hematological effects and reduced sperm counts. Four of the exposed individuals died (Toxnet, 2006).

\subsection{Ground Contamination}

After the Fukushima Plant Disaster, large quantities of radionuclides, mainly ${ }^{131} \mathrm{I},{ }^{137} \mathrm{Cs}$ and ${ }^{134} \mathrm{Cs}$, were released into the air (Hamada \& Ogino, 2012). These radionuclides aerosolize into fine particles or become soluble gases, thus being able to form dry or wet deposits in any surface which is in contact with contaminated air. Dry and wet deposition is the mechanism by which air contamination is able to contaminate the land (IRSN, 2012). The implication of radionuclide deposition is that plant products can be contaminated by direct deposition on the plant surface or by absorbing radionuclides that were deposited and adsorbed in soil (Nakanishi et al, 2012). In a study by Nakanishi et al (2012), radioactive Cs was measured from wheat, rice, peach tree and soil, two months after the Fukushima incident. The study found that high levels of radioactive Cesiums were detected on the leaves, branch, trunk, rice grain and soil due to fallout deposition on plant surfaces. Cesium accumulation on milled rice (Cs deposits falls on the bran surface) was also found suggesting that contamination happened due to Cs absorption from water and soil as well.

Animal products can also be contaminated due to fallout deposition. Animals may consume contaminated plant products and water, leading to the possibility of livestock products such as meats, milk, eggs being contaminated (IRSN, 2012). One such example is contaminated milk that was found weeks after the Fukushima incident. Milk with ${ }^{131}$ I concentrations five times higher than the Japanese guidelines was found on farms in the Fukushima Prefecture (Belson \& Tabuchi, 2011). From March 2011 to February 2012, around 2000 milk product samples were analyzed in Japan; resulting in 23 samples exceeding Japanese guidelines (IRSN, 2012).

\subsection{Contamination of the Marine Environment}

Immediately after the Fukushima Nuclear Disaster, there has been major concern about the marine biota. At the time of the disaster, winds were blowing in the direction towards the sea, resulting in large amounts of radionuclides being released directly into the ocean (Batlle et al, 2014). The main radionuclides released into the ocean were ${ }^{131} \mathrm{I}$ and ${ }^{137} \mathrm{Cs}$. However, due to ${ }^{131} \mathrm{I}$ 's short half-life, 2 months after the Fukushima incident, it was no longer detectable (IRSN, 2012).

In a study by Wada et al (2013), 6462 specimens within 169 marine species were collected off the coast of Fukushima from April 2011 until October 2012 and analyzed for ${ }^{131} \mathrm{I},{ }^{134} \mathrm{Cs}$ and ${ }^{137}$ Cs. In 2011, 63 specimens exceeded the Japanese regulatory limit $(100 \mathrm{~Bq} / \mathrm{kg})$ for ${ }^{134} \mathrm{Cs}$ and ${ }^{137} \mathrm{Cs}$; and in 2012, 41 specimens exceeded 
the limit. The researchers found that radionuclides concentrations decreased significantly with time but differed amongst taxa and habitats; coastal benthic fishes having the most gradual radiation decreases and the most frequent concentration above limit detections (Wada et al, 2013). In another study by Tateda et al (2012), ${ }^{137} \mathrm{Cs}$ concentrations of invertebrates, benthic fish and predator fish from the southern Fukushima area were monitored immediately after the 2011 incident. It was found that ${ }^{137} \mathrm{Cs}$ concentrations reached its maximum (Algae $=$ $880 \mathrm{~Bq} / \mathrm{kg}$, benthic fish $=3200 \mathrm{~Bq} / \mathrm{kg}$, predator fish $=1600 \mathrm{Bg} / \mathrm{kg}$ ) during the months of late April, May and late July of 2011; concentrations after July began to steadily decrease (Tateda et al, 2012). Although cesium contamination has decreased significantly around Japan's sea, monitoring of the marine species fished in the area is still recommended (IRSN, 2012).

In Canada, the Canadian Albacore Tuna Association has been monitoring radiation in sea food that may come from the Pacific of Japan (BC Wild Albacore Tuna, 2013). Monitoring began in 2010 (before that Fukushima Plant disaster) and continues until the present. Testing is done for the main radionuclides ${ }^{131} \mathrm{I},{ }^{134} \mathrm{Cs}$ and ${ }^{137} \mathrm{Cs}$ that were released in the Fukushima incident. Up to date, no sample had detectable levels of the three radionuclides (detection limit $=0.002 \mathrm{~Bq} / \mathrm{g})(\mathrm{BC}$ Wild Albacore Tuna, 2013). Additionally, in a recent study by Luan and her colleagues (2013), 52 samples within 10 species of fish and 3 species of shellfish from markets in the Greater Vancouver Regional District were tested for the presence of radionuclides ${ }^{134} \mathrm{Cs}$ and ${ }^{137}$ Cs. The study showed that none of the samples contained the radioactive cesium isotopes (Detection limit $=0.01 \mu \mathrm{Sv} / \mathrm{hr}$ near the surface of the meter, corresponding to approximately $1 \mathrm{~Bq}$ ) (Luan, Sidhu, \& Zitouni, 2013).

\section{Canadian Guidelines}

In order to control radioactively contaminated commercial foods and water in situations of nuclear emergency, Health Canada has set guidelines for three food groups (BCCDC, 2014). Refer to Table 1 for action levels of ${ }^{131} \mathrm{I},{ }^{137} \mathrm{Cs}$ and ${ }^{134} \mathrm{Cs}$. The Canadian Guidelines were developed with recommendations from the Food and Agriculture Organization (FAO)/World Health Organization (WHO) Codex Alimentarius Comission; its purpose is to protect the public from radiation-induced cancer and genetic disorders in the offspring as a result of consuming radioactively contaminated food/water (BCCDC, 2014).

Table 1: Recommended Action Levels for Three Food Groups in Canada

\begin{tabular}{cccc}
\hline \multirow{2}{*}{ Radionuclide } & \multicolumn{3}{c}{ Action Levels (Bq per kg) } \\
\cline { 2 - 4 } & Fresh Liquid Milk & Public Drinking Water & $\begin{array}{c}\text { Other Commercial } \\
\text { Foods and Beverages }\end{array}$ \\
${ }^{131} \mathbf{I}$ & 100 & 100 & 1000 \\
${ }^{137} \mathrm{Cs}$ & 300 & 100 & 1000 \\
${ }^{134} \mathrm{Cs}$ & 300 & 100 & 1000 \\
\hline
\end{tabular}




\section{Role of Public Health Inspectors}

This research project aims to inform Public Health Inspectors (PHI) about the facts regarding contaminated foods from Japan due to the Fukushima nuclear plant disaster. The PHI's role is to protect and promote public health. By arming Canadian PHIs with the knowledge of the conditions of Japanese foods, they will be able to more effectively educate the public by presenting all of the up-to date facts on the matter so that the public can make a wellinformed decision on whether or not to purchase foods imported from Japan.

\section{Purpose}

After the Fukushima nuclear plant meltdown on March 2011, Canadians are still concerned about food products coming from Japan. Little radiation monitoring in foods happens in BC because testing for radiation is expensive and Health Canada has determined that radioactivity levels in foods in Canada are below the national guidelines. The purpose of this research project is to test for the presence/absence of total radiation in various food products imported to Canada from Japan. The result of this study will determine whether food products from Japan contain radionuclide traces so that Canadian consumers can be aware of it when purchasing such products in the Canadian market.

\section{Methods}

Food samples were purchased from supermarkets and convenience stores in Vancouver - BC, Canada. 30 imported Japanese food products were purchased from Fujiya and
Kim's Mart. 32 food products commonly found in Canadian stores were purchased from Superstore and Costco. All food products were prepared to be analyzed with the GR-135 Plus. Each food product was removed from its package, and a one serving size portion, according to package label, was placed in a plate or a cup. After all of the 60 samples were prepared, each sample was measured with the GR-135 Plus for the presence/absence of gamma radiation from ${ }^{134} \mathrm{Cs}$ and ${ }^{137} \mathrm{Cs}$ specifically. Analysis was done by lifting the GR-135 Plus from its docking station, setting it to "survey mode" and approaching the machine as close as possible to each food sample. When in close proximity to the food sample, the "identify" function was used in order to attempt to detect any radionuclides present. If the machine detected any amount of gamma radiation from ${ }^{134} \mathrm{Cs}$ and ${ }^{137} \mathrm{Cs}$ radionuclides, the sample was considered to have gamma radiation contamination present. If no gamma radiation was detected from the sample, it was considered "absent" of gamma radiation contamination.

\section{Results}

All 62 samples of the imported Japanese food products and food products commonly available in Canadian stores were analyzed with the $G R$ 135 Plus for the presence or absence of gamma radiation from ${ }^{134} \mathrm{Cs}$ and ${ }^{137} \mathrm{Cs}$. Analysis with the "identify" function resulted in the GR-135 Plus displaying "background" for all samples tested. This indicates that radiation from ${ }^{134} \mathrm{Cs},{ }^{137} \mathrm{Cs}$ or other radionuclides were not present in any of the samples during the time of the experiment. Refer to tables 2 and 3 below, for a summary of the results. 
Table 2: Food Products Imported from Japan

\begin{tabular}{|c|c|c|c|}
\hline $\begin{array}{c}\text { Sample } \\
\#\end{array}$ & Product name & Product Description & $\begin{array}{c}\text { Gamma radiation } \\
\text { (Present or Absent) }\end{array}$ \\
\hline 1 & Tennenkoubo Pan Chocolate & $\begin{array}{l}\text { Baked wheat cake - chocolate } \\
\text { flavor }\end{array}$ & Absent \\
\hline 2 & Maronn Annpai & Chestnut cake & Absent \\
\hline 3 & Mayonnaise & Mayonnaise (Half-calories) & Absent \\
\hline 4 & Iri Goma (Shiro) & Rosted Sesame Seeds (White) & Absent \\
\hline 5 & Iri Goma (Kuro) & Roasted Sesame Seeds (Black) & Absent \\
\hline 6 & Ryokuto Harusame & Japanese Vermicelli dry noodles & Absent \\
\hline 7 & Yamaimo Soba & Buck Wheat Noodle & Absent \\
\hline 8 & Aonori & Dried sea weed powder & Absent \\
\hline 9 & Tororo Connbu & Algue & Absent \\
\hline 10 & Beni Ebi & Dry shrimp & Absent \\
\hline 11 & Tennkasu & Fried Wheat Flour & Absent \\
\hline 12 & Niwatori no Shiodare Itame no Moto & Gochiuma - Salt Sauce & Absent \\
\hline 13 & Wakame & Soy Bean Paste & Absent \\
\hline 14 & Otona no Furikake (Beni Shake) & Topping for rice & Absent \\
\hline 15 & Chuka Zannmai & Instant Noodles (Soy Sauce) & Absent \\
\hline 16 & Bamu Roru & White Cake roll & Absent \\
\hline 17 & Crème Stew & Stew Mix & Absent \\
\hline 18 & Yaki Sushi Nori & Roasted Sea Weed & Absent \\
\hline 19 & Sannma Kabayaki & Canned Baked Seasoned Saury & Absent \\
\hline 20 & Yude Azuki & Canned Red Bean & Absent \\
\hline 21 & Ajisuke Ika & Canned Squid in Soy Sauce & Absent \\
\hline 22 & Torokeru Kare & Curry Medium & Absent \\
\hline 23 & Shoyu & Soy Sauce & Absent \\
\hline 24 & Goma Abura & Sesame Oil & Absent \\
\hline 25 & Kurosu Iri Mozuku & Seasoned Sea weed & Absent \\
\hline 26 & Aka Miso & Soybean paste (Red) & Absent \\
\hline 27 & Aokappa Tsukemono & Pickled Cocumber & Absent \\
\hline 28 & Ika Kimuchi & Squid marinated in Kimchi paste & Absent \\
\hline 29 & Kyushu Ichibann Natto & Fermented Soy Beans & Absent \\
\hline 30 & Gennmai-Cha & Green tea Bag & Absent \\
\hline
\end{tabular}

Table 3: Food Products Commonly Available in Canadian Stores

\begin{tabular}{|c|c|c|c|}
\hline $\begin{array}{l}\text { Sample } \\
\quad \#\end{array}$ & Product name & Product Description & $\begin{array}{r}\text { Gamma radiation } \\
\text { (Present or Absent) }\end{array}$ \\
\hline 1 & 2\% Partially Skimmed Milk & Skim milk $-2 \%$ & Absent \\
\hline 2 & 100\% Whole Grain Canadian Oats - Quick Oats & Oatmeal & Absent \\
\hline 3 & Wild Pacific Pink Salmon & Canned wild salmon & Absent \\
\hline 4 & Green Tea & Green tea bag & Absent \\
\hline 5 & White bread & Sliced bread - white & Absent \\
\hline 6 & Coffee Crisp & Coffee chocolate bar & Absent \\
\hline 7 & Rosemary Roasted Chicken with Potatoes & $\begin{array}{l}\text { Garlic, paprika and } \\
\text { rosemary spices }\end{array}$ & Absent \\
\hline 8 & Spaghettini & $100 \%$ whole grains pasta & Absent \\
\hline 9 & Paste made from Tomatoes - Herbs \& Spices & Canned tomato paste & Absent \\
\hline 10 & Chunky Chicken Noodle Soup & $\begin{array}{l}\text { Canned chicken noodle } \\
\text { soup }\end{array}$ & Absent \\
\hline 11 & Red Kidney Beans & Canned kidney beans & Absent \\
\hline 12 & Raspberry Jam & Raspberry jam & Absent \\
\hline 13 & Fruit Plus Veggies \& Fibre & Veggies and fruits juice & Absent \\
\hline 14 & Pure Olive Oil & Olive oil & Absent \\
\hline 15 & Mayonnaise $1 / 2$ Fat & Mayonnaise $-1 / 2$ fat & Absent \\
\hline 16 & Tofu Dessert Peach and Mango & $\begin{array}{l}\text { Tofu - mango and peach } \\
\text { flavored }\end{array}$ & Absent \\
\hline
\end{tabular}




\begin{tabular}{lccc}
\hline 17 & Mandarin Ponkkan & Mandarin orange & Absent \\
18 & Craft Baked Bread & $\begin{array}{c}\text { Sliced bread - oat \& nut } \\
\text { with honey }\end{array}$ & Absent \\
19 & Banana & Banana & Absent \\
20 & Smoked Oysters & Canned smoked oysters & Absent \\
21 & Canada No.1 Maple Syrup & Maple syrup & Absent \\
22 & Solid Light Tuna in Water & Canned tuna & Absent \\
23 & Bowl Noodle Soup & Spicy kimchi instant & Absent \\
& & noodles & Absent \\
24 & Original Pancake \& Waffle Mix & Pancake mix & Absent \\
25 & Activia Yogurt - Strawberry & Strawberry yogurt & Absent \\
26 & Organic Chia seeds & Chia seeds & Absent \\
28 & Seasoned Chicken & Roasted chicken - whole & Absent \\
29 & Broccoli & Broccoli & Absent \\
30 & Top Sirloin Grilling Steak (Triple A) & Mechanically tenderized & Absent \\
31 & steak & Baby spinach & Absent \\
\hline 32 & Organic Baby Spinach & Eggs with omega-3 & Absent \\
\hline
\end{tabular}

\section{Discussion}

The findings in this study suggest that foods imported from Japan to Canadian stores are likely not contaminated with ${ }^{134} \mathrm{Cs},{ }^{137} \mathrm{Cs}$ or other radionuclides that were released from the Fukushima incident four years ago. There may be several reasons to why ${ }^{134} \mathrm{Cs}$ and ${ }^{137} \mathrm{Cs}$ contamination from the Fukushima incident were not found in the food products from Japan. The most likely reason would be that radionuclides that were released into the environment have been diluted to the point below detection levels (Zitouni, 2014). Due to wind patterns during the Fukushima incident, large quantities of radionuclides were released over the Pacific Ocean. Radiation levels in the Pacific Ocean close to the plant may have peaked immediately after the incident; however due to its enormous volume and water currents, it is very likely that the radionuclide concentration have been vastly diluted. In a study by Germany's Geomar Helmholtz Centre for Ocean Research (Behrens, 2012), global ocean circulation models were constructed to estimate the long term dispersion of ${ }^{137} \mathrm{Cs}$ from the local waters off the Fukushima plant. The model predicted that two years after the incident, ${ }^{137} \mathrm{Cs}$ levels would fall to 10 becquerel per cubic meter; and within four years, ${ }^{137} \mathrm{Cs}$ levels would fall to 1-2 becquerel per cubic meter which is about twice the levels prior to the incident (Behrens, 2012). Consequently, on a risk assessment study performed three months after the Fukushima incident, the researchers measured radionuclide levels of squid samples and seawater from the ocean waters located at the east of Japan ( $\mathrm{Yu}$ et al, 2015). ${ }^{137} \mathrm{Cs}$ concentration in sea water was found to range from 1 to $826 \mathrm{mBq} / \mathrm{L}$ and ${ }^{137} \mathrm{Cs}$ concentration was found to be on average $1.65 \mathrm{~Bq} / \mathrm{kg}$ (Yu et al, 2015). The study concluded that the emissions from the Fukushima plant did not have significant adverse effects on the marine biota at the population level (Yu et al, 2015).

Another reason that could explain the absence of radionuclides in Japanese food products is the natural decay of radionuclides such as I-131 and Cs-134 in addition to dilutions in the air, water and soil. This explains why ${ }^{131} \mathrm{I}$ was not expected to be detected in this study. It has a short half-life of eight days (US EPA, 2002), thus it is very unlikely that at present times, it would still be found in the environment or in foods. ${ }^{134} \mathrm{Cs}$ and ${ }^{137} \mathrm{Cs}$ on the other hand, have a longer half-life (US EPA, 2002). Therefore, if gamma radiation was found in the Japanese food 
products in the present study, ${ }^{134} \mathrm{Cs}$ and ${ }^{137} \mathrm{Cs}$ would be the major suspects. Land can be contaminated through dry and wet deposition of radioactive material. Immediately after the Fukushima incident, food products exposed to the air could have been highly contaminated through deposition. However, years after the incident, food products such as crops are contaminated by growing in contaminated soil or if irrigated with contaminated water. Livestock are contaminated if fed with contaminated crop products. The absence of radiation in Japanese food products suggest that natural degradation of radionuclides may have contributed to the levels below detection limits currently found.

Lastly, radiation may not have been detected in the present study because none of the Japanese food products tested was produced in the Fukushima prefecture region. According to the Japanese Ministry of Health - Labour and Welfare (JMHLW), the whole country's food supply did not get equally affected by the Fukushima incident's fallout (Kendall, 2012). In fact, Fukushima and surrounding prefectures had the most food samples exceeding national guidelines for ${ }^{134} \mathrm{Cs},{ }^{137} \mathrm{Cs}$ or ${ }^{131} \mathrm{I}$. From March 2011 to March 2012, Fukushima had 718 unsatisfactory food samples which are $3.33 \%$ of the samples tested. Prefectures far away from Fukushima such as Kyoto and Aomori had no food sample exceeding national guidelines (Kendall, 2012). These findings indicate that fallout from the Fukushima incident did not cover a significantly large area. Furthermore, extrapolating the findings by JMHLW, it is very unlikely that any significant radionuclide contamination from Fukushima travelled as far as to other countries. The present study's finding that radiation was not detected in food products commonly available Canada also supports the assumption that no significant radioactive contamination from Fukushima reached far away countries such as Canada. Moreover, according to the United Nations, the Fukushima incident in Japan did not affect radiation levels in other countries; which still to date, have background levels far below background levels that most people experience daily (World Health Organization, 2011).

It is important to note that even if ${ }^{134} \mathrm{Cs}$ and ${ }^{137} \mathrm{Cs}$ contamination were found in Japanese food products, it would not be immediately considered detrimental to the health (personal communication with Dr. Zitouni, 2014). In such event, further in-depth analysis of the samples in a gamma spectrometry laboratory would be required. Furthermore, internal doses due to gamma radiation would have to be calculated to determine the actual potential harm to humans (Zitouni, 2014).

The findings in the present study also have the purpose to inform Public Health Inspectors (PHI) regarding the risks of consuming foods contaminated with radiation from the Fukushima incident. In the field of risk communication, risk, in this case, probability of adverse health effects from consumption of food contaminated with radiation, is "Hazard + Outrage" (Sandman, 2000). Hazard would be the actual health outcome such as increased cancer rate; and outrage would be anything negative perceived by the public regarding its risks. According to the findings in the present study and the literature, "hazard" is extremely low as no radiation was found in food samples from Japan; or if radiation traces were found, they were so low that it did not pose a long term health risk. However, due to media bias, rumors, lack of education and lack of radiation monitoring programs in Canada, the public's perception of food contaminated with radiation is extremely negative; in other words, outrage is very high. Consequently, although hazard is very low, because outrage is high, "risk" from eating food contaminated with radiation is considered to be 
naturally high. In order to reduce the risk perceived by the public, outrage has to be reduced. The most effective way to accomplish this is by educating the public about the actual hazards associated to consumption of food products from Japan.

It has been four years since the Fukushima incident and Canadians are still concerned about food products from Japan. This research hopes to provide Canadian PHIs with the knowledge of the conditions of Japanese foods, so that they are able to more effectively educate the public. By presenting all of the up-to date facts on the matter, the public would be able to make a wellinformed decision on whether or not to purchase food imported from Japan.

\section{Recommendations}

Future studies that would enhance the findings of this research could test for the presence of radiation in produce products such as fruits and vegetables from Japan. Another study could be done with a wider variety and sample number of food products from Japan (including products imported from Fukushima and surrounding prefectures).. Lastly, a study where radiation levels in Japanese food products are quantified rather than tested for presence/absence could be performed by means of large $\mathrm{NaI}-\mathrm{Tl}$ or $\mathrm{HpGe}$ detectors connected to advanced spectrum analyzers.

\section{Limitations}

Due to budget constraints, only 30 Japanese food products and 32 common food products in Canadian stores were tested. Additionally, the choice of food samples was based on affordability and availability. A wider variety of food products from both food groups would make a better representation of food products from Japan and other countries when testing for the presence of radiation. Moreover, no food product tested was directly produced in the
Fukushima prefecture in Japan. It would be interesting to test for radiation in products from Fukushima and closely surrounding prefectures as these areas were likely more affected by the radioactive fallout following the Fukushima incident.

\section{Conclusion}

Four years after the Fukushima nuclear power plant disaster, many Canadians remain concerned about elevated radiation levels in food coming from Japan. The present study demonstrates that food products imported from Japan does not contain radiation traces from cesium-134 and cesium-137 released to the Fukushima incident back in 2011. Possible reasons for the absence of radiation in food could be due to dilution coupled with the natural degradation of radionuclides in the environment or the fact that only Fukushima and surrounding prefectures were affected by the nuclear plant's radioactive fallout. The findings in this research can be of benefit to Public Health Inspectors when educating the concerned public regarding radiation contamination in food; so that the public can make well-informed decisions when purchasing food products imported from Japan.

\section{Acknowledgements}

I would like to express my profound gratitude and deep regards to my project mentor Dr. Abderrachid Zitouni, B.C. Centre for Disease Control Provincial Radiation Specialist. Not only did Dr. Zitouni suggest the topic for this research project, allow me to borrow the GR-135 Plus Identifier instrument, but he also provided me with a lot of insight in this research project. I am very grateful for the opportunity to work with him and the attention he has given to my work. I would also like to thank my research instructor and supervisor, Bobby Sidhu, for his encouragement and guidance in the past six months. 


\section{Competing interest}

The authors declare that they have no competing interests.

\section{References}

Agency for Toxic Substances \& Disease Registry. (2011). Public Health Statement for Cesium. Retrieved from: http://www.atsdr.cdc.gov/phs/phs.asp?id=575\&tid=10 7

Batlle, J., Aono, T., Brown, J. E., Hosseini, A., GarnierLaplace, J., Sazykina, T., et al. (2014). The impact of the Fukushima nuclear accident on marine biota:. Science of the Total Environment, 487, 143-153.

Behrens, E., Schwarzkopf, F., Lübbecke, J. F., Böning, C. W. (2012). Model simulations on the long-term dispersal of 137Cs released into the Pacific Ocean off Fukushima. Environmental Research Letters, 7. Retrieved from: http://iopscience.iop.org/17489326/7/3/034004

Belson, K. \& Tabuchi, H. (2011) Japan Finds Tainted Food Up to 90 Miles From Nuclear Sites. The New York Times. Retrieved from http://www.nytimes.com/2011/03/20/world/asia/20jap an.html?pagewanted=all\&_r=0

BC Centre for Disease Control. (2014). Status of Radiological Activity in Japan - FAQ. Retrieved from: http://www.bccdc.ca/healthenv/Radiation/JapanFAQ/d efault.htm

BC Wild Albacore Tuna. (2013). Latest correct radiation info regarding all Albacore caught in the Pacific Northwest. Retrieved from: http://www.bctuna.com/Tuna-Radiation-Report.htm

Cable News Network. (2011). Fukushima Nuclear Reactor Problem Explained. Video retrieved from: https://www.youtube.com/watch?v=BdbitRlbLDc.

Canadian Food Inspection Agency. (2011). Japan Nuclear Crisis: Information for Canadians Regarding Imported and Domestic Food. Retrieved from: http://epe.lacbac.gc.ca/100/206/301/cfia-acia/2011-09- 21/www.inspection.gc.ca/english/fssa/imp/eartere.sht $\underline{\mathrm{ml}}$

Chiu, H., Huang, P., Wuu, J., \& Wang, J. (2013). Radioactivity inspection of Taiwan for food products imported from Japan after the Fukushima nuclear accident. Applied Radiation and Isotopes, 81, 356-357.

Dobashi, R. (2011). Fire and explosion disasters occurred due to the Great East Japan Earthquake. Journal of Loss Prevention in the Process Industries, 31, 121-126.

EnergySolutions. (2014). Exploranium GR-135PLUS Identifier. Retrieved from: http://shopping.netsuite.com/s.nl/c.817517/sc.7/catego ry.12695/.f.

Hamada, N., \& Ogino, N. (2012). Food safety regulations: what we learned from the Fukushima nuclear accident. Journal of Environmental Radioactivity, 111, 83-99.

Health Canada. (2014). Additional information on radiation from Japan. Retrieved from: http://www.hcsc.gc.ca/hc-ps/ed-ud/respond/nuclea/add_inforen supp-eng.php

IRSN. (2012). Summary of the Fukushima accident's impact on the environment in Japan, one year after the accident. Retrieved from: http://www.irsn.fr/EN/publications/thematic/fukushim a/Documents/IRSN_Fukushima-Environmentconsequences 28022012.pdf

Kendall, P. (2012). Distribution of Japanese test result by prefecture. Retrieved from http://thetyee.ca/Mediacheck/2013/04/27/KendallLette r.pdf

Luan, A., Sidhu, B., \& Zitouni, A. (2013). Testing for presence of radioactivity in BC Pacific Ocean's seafood supply. British Columbia Institute of Technology - Environmental Health .

Leidos. (2014). EXPLORANIUM® GR-135 Plus "Identifier" Radioisotope Identification Device. Retrieved rom: https://www.leidos.com/products/security/gr-135. 
Marzo, G. A. (2014). Atmospheric transport and deposition of radionuclides released after the Fukushima Dai-chi accident and resulting effective dose. Atmospheric

Environment, 94, 709-722.

Nakanishi, T. M., Kobayashi, N. I. \& Tanoi, K. (2012) Radioactive cesium deposition on rice, wheat, peach tree and soil after nuclear accident in Fukushima. Journal of Radioanalytical and Nuclear Chemistry, 2, $985-989$.

National Police Agency of Japan. (2014). Damage

Situation and Police Countermeasures associated with 2011Tohoku district - off the Pacific Ocean Earthquake. Retrieved from http://www.npa.go.jp/archive/keibi/biki/index_e.htm.

Pynn, L. (2014, March). Troubled waters: Nuclear radiation found in B.C. may pose health concerns. The Vancouver Sun. Retrieved from: http://www.vancouversun.com/news/Troubled+waters + Nuclear+radiation+found+pose+health+concerns/96 $\underline{06269 / \text { story.html }}$

Sandman, P., M. (2000). Risk = Hazard + Outrage: Coping with Controversy about Utility Risks. Retrieved from: http://www.psandman.com/articles/amsa.htm

Takeuchi, K., Sidhu, B., \& Zitouni, A. (2013). Testing for Presence of Radioactivity in Food Products Imported from Japan to Canada. British Columbia Institute of Technology - Environmental Health .

Tateda, Y., Tsumune, D., \& Tsubono, T. (2013).

Simulation of radioactive cesium transfer in the southern Fukushima coastal biota using a dynamic food chain transfer model. Journal of Environmental Radioactivity, 124, 1-12.

Toxnet. 2006. Cesium Radioactive Human Health Effects. Retrieved from: http://toxnet.nlm.nih.gov/cgibin/sis/search/a?dbs+hsdb:@term+@DOCNO+7389

US Environmental Protection Agency. (2002). EPA Facts About Cesium-137. Retrieved from: http://www.epa.gov/superfund/health/contaminants/ra diation/pdfs/cesium.pdf
US Environmental Protection Agency. (2002). EPA Facts About Iodine. Retrieved from: http://www.epa.gov/superfund/health/contaminants/ra diation/pdfs/iodine.pdf

Wada, T., Nemoto, Y., Shimamura, S., Fujita, T., Mizuno, T., Sohtome, T., et al. (2013). Effects of the nuclear disaster on marine products in Fukushima. Journal of Environmental Radioactivity, 124, 246-254.

World Health Organization. (2011). FAQs: Japan Nuclear Concerns. Retrieved from: http://www.who.int/hac/crises/jpn/faqs/en/index7.html

Yu,W., He, J., Lin, W., Li, Y., Men. W., Wang. F., Huang, J. (2015) Distribution and risk assessment of radionuclides released by Fukushima nuclear accident at the northwest Pacific. Journal of Environmental Radioactivity, Volume 142, 54-61. Retrieved from: http://dx.doi.org/10.1016/j.jenvrad.2015.01.005.

Zitouni, R. (2014). B. C. Centre for Disease Control. Environmental Health Services Division. 